\title{
Spontaneous heterotopic triplet pregnancy: rare case report
}

\author{
Sasirekha Rengaraj ${ }^{1}$, Stalin Vinayagam ${ }^{1}$, Sadaf Soukath $^{2}$ \\ ${ }^{1}$ Department of Obstetrics and Gynaecology, JIPMER, Puducherry, India \\ ${ }^{2}$ Department of Obstetrics and Gynaecology, SDH, Kreeri, Kashmir, India
}

Received: 02 October 2016

Accepted: 27 October 2016

\section{*Correspondence:}

Dr. Sasirekha Rengaraj,

E-mail: drsasirekha.r_ms@ymail.com

Copyright: ( $)$ the author(s), publisher and licensee Medip Academy. This is an open-access article distributed under the terms of the Creative Commons Attribution Non-Commercial License, which permits unrestricted non-commercial use, distribution, and reproduction in any medium, provided the original work is properly cited.

\begin{abstract}
Heterotopic pregnancy, simultaneous occurrence of both intra uterine and extra uterine pregnancy is on rise because of assisted reproductive technology and widespread usage of first trimester USG. However such pregnancies are rare following spontaneous occurrence. High degree of clinical suspicion is essential in such spontaneous conceptions to diagnose it in early pregnancy to maximize the outcome for intra uterine pregnancy. Here we are presenting a case of simultaneous occurrence of twin intrauterine pregnancy and co existing tubal abortion with good perinatal outcome from a remote area.
\end{abstract}

Keywords: Heterotopic pregnancy, Spontaneous conception, Twin, Tubal abortion, USG

\section{INTRODUCTION}

Heterotopic pregnancy is defined as simultaneous existence of both intra uterine and extra uterine pregnancy. It is potentially dangerous and also rare in spontaneous conceptions. The original incidence is 1 in 30,000 pregnancies with ART the incidence is found to be as high as $1 \%$. Historically it was first reported in the year 1708 as an autopsy finding. Majority (70\%) of heterotopic pregnancies were diagnosed between 5 and 8 weeks of gestation; only $10 \%$ after 11 weeks of gestation. The fact that only $10 \%$ of heterotopic pregnancies are diagnosed preoperatively shows the importance of high resolution trans vaginal USG. ${ }^{2}$ It is essential to have high index of suspicion especially in spontaneous conceptions.

\section{CASE REPORT}

26 years G3L2 presented to OPD with H/O 2 months of amenorrhoea and spotting $\mathrm{P} / \mathrm{V}$ and no history of giddiness or syncopal attack. Vitals were stable except for mild pallor. Abdomen was soft except minimal tenderness in lower abdomen. There was no guarding or rigidity on examination. On bimanual pelvic examination, uterus was 10 weeks size and there was vague fullness in right fornix and was tender. USG showed live twin intrauterine gestation with complex mass in right adnexa with minimal free fluid (Figure 1 and Figure 2). Emergency laparotomy was done after basic investigations. There was $250 \mathrm{ml}$ of hemoperitoneum, Uterus was 10 weeks size. There was right ampullary ectopic with features of tubal abortion. Right total salphingectomy was done. Care was taken not to disturb the pregnant uterus throughout the surgery. The viability of twin intrauterine pregnancies ( 8 weeks) was confirmed after surgery. She was discharged on post op D4; Her Hb was $8 \mathrm{gm} \%$. She was put on progesterone support till the end of second trimester. Routine supplementation was given and received 5 doses of iron sucrose at 34 weeks. Except anemia antenatal period was uneventful. She went into labour spontaneously at 37 weeks and delivered female babies of 2.5 and $2.6 \mathrm{~kg}$ with APGAR of 7 and 8 and 6 and 8 ; both are alive and healthy. 


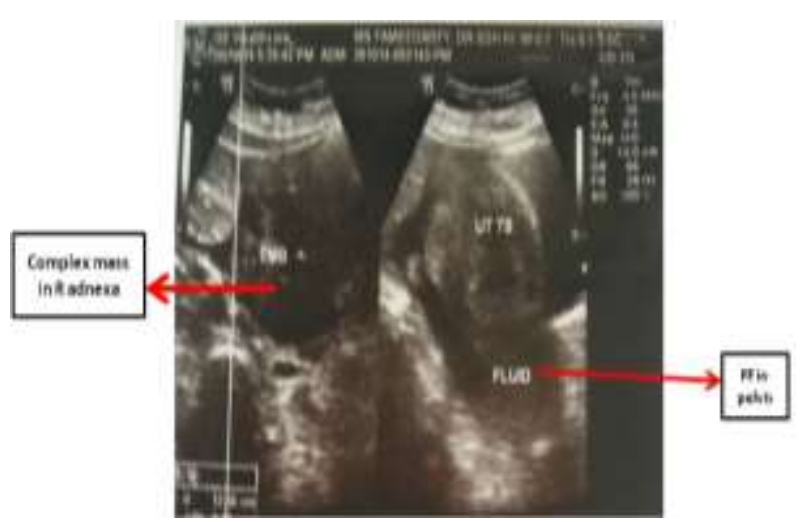

Figure 1: USG image of intrauterine pregnancy and complex adnexal mass.

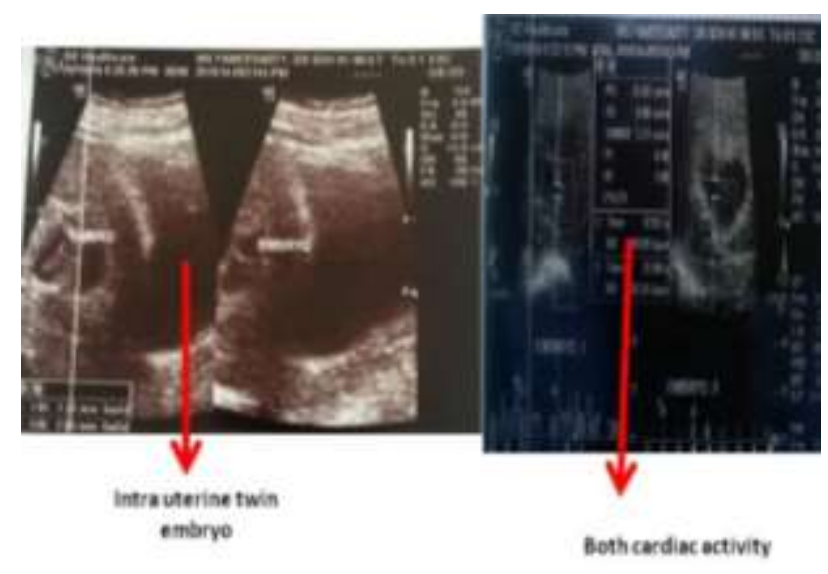

Figure 2: twin embryo with fetal cardiac activity.

\section{DISCUSSION}

In the recent years, the increased incidence of multiple pregnancies with ART increases the risk of both ectopic and heterotopic pregnancy. The etiology is multifactorial. Like ectopic pregnancy, H/O PID, any tubal surgery and previous $\mathrm{H} / \mathrm{O}$ ectopic pregnancy are the risk factors for heterotopic pregnancy. The hydrostatic forces generated during embryo transfer may also contribute to the recent increase of heterotopic pregnancy. In spontaneous conceptions usually it is diagnosed at laparotomy or after the procedure unless the suspicion is very high.

The confirmation of intra uterine pregnancy on USG is often taken as exclusion of ectopic pregnancy. This leads on to delay in diagnosis of heterotopic pregnancy which often results in catastrophic outcome of both intrauterine and extra uterine pregnancies.

Generally, it should be suspected following assisted reproductive conceptions, persistent or rising gonadotropin levels after induced/ spontaneous abortions, absent vaginal bleeding in the presence of signs and symptoms of ectopic pregnancy and when more than one corpus luteum is present in natural conceptions. ${ }^{3}$ Intrauterine gestation with hemorrhagic corpus luteum can stimulate heterotopic gestation both clinically and on
USG. Sometime bicornuate uterus with gestation in both cavities may also simulate a heterotopic pregnancy.

Ectopic pregnancy remains the most common cause of mortality in first trimester. Fallopian tube is the commonest site of heterotopic pregnancy but there have been case reports of ovarian and cervical. Usually the intrauterine pregnancy is singleton; however there are associated twin/ triplet intrauterine pregnancies following ART. The existence of twin intra uterine and tubal pregnancy in spontaneous conception is very rare and only two cases have been reported so far. $50 \%$ of heterotopic pregnancies are asymptomatic. Delay in diagnosis is not uncommon because heterotopic pregnancies may be obscured in the presence of intrauterine pregnancies and mass is often confused for hemorrhagic corpus luteum which may be present in otherwise normal intrauterine pregnancy. Both Laparoscopic/ laparotomy are acceptable modalities of treatment and it depends on clinical condition and availability of facility. But both carry surgical and anaesthetic risk to both the mother and fetus. Even though various studies have shown pregnancy loss upto $40 \%$ laparotomy generally does not seem to have an adverse effect on viable intrauterine pregnancies. ${ }^{4}$

The outcome of intrauterine pregnancy is good if the heterotopic is diagnosed before it ruptures and the prognosis is usually $60-70 \% .^{5}$ Systemic medical management is not preferred usually because of coexisting intrauterine pregnancy. Local injection of $\mathrm{KCl}$ is preferred over methotrexate.

Even though it's one of the important obstetric emergencies in early pregnancy there have been case reports of successful expectant management of heterotopic pregnancy. ${ }^{6}$ Those who have un ruptured gestation on USG along with persistent downward trend in beta hCG assay can be offered expectant management.

Heterotopic pregnancy can occur even in the absence of any predisposing factors. Presence of intrauterine pregnancy does not exclude the possibility of heterotopic pregnancy. With better diagnostic modalities an early and accurate diagnosis is possible. Strong clinical suspicion and through assessment of whole pelvis including adnexae are essential at the time of ultrasound. They are the key to successful management of intra uterine pregnancy.

\section{ACKNOWLEDGEMENT}

This surgery was undertaken in Kreeri, SDH remote place in Baramulla district, KASHMIR when we were deputed for 2 weeks after flood $\left(20^{\text {th }}\right.$ Sep 2014). We would like to express our sincere thanks to Dr. Manzoor, CMO and Dr. Saba Vani BMO for their full co-operation, involvement and timely arrangement of theatre and technicians to go ahead with surgery much beyond the working time with minimal resources. 
Funding: No funding sources

Conflict of interest: None declared

Ethical approval: Not required

\section{REFERENCES}

1. Tandon R, Goel P, Saha PK, Devi L. Spontaneous heterotopic pregnancy with tubal rupture: a case report and review of the literature $\mathrm{J}$ Med Case Reports. 2009.

2. Anastasakis E, Jetti A, Daskalakis ML, A case of heterotopic pregnancy in the absence of risk factors. A brief literature review. Fetal. Diagn. Ther. 2007;22:285-8.

3. Govindarajan MJ, Rajan R. Heterotopic pregnancy in natural conception J Hum Reprod Sci. 2008;1(1):378.
4. Yao M, Tulandi T. Current status of surgical and nonsurgical management of ectopic pregnancy Fertil Steril. 1997 Mar;67(3):421-33.

5. Clausen I. Conservative versus radical surgery for tubal pregnancy: a review. Acta Obstet Gynecol Scand. 1996;75:8-12.

6. Fernandez H, Lelaidier C, Doumerc S, Fournet P, Olivennes F, Frydman R. Nonsurgical treatment of heterotopic pregnancy: a report of six cases. Fertility and sterility. 1993;60(3):428-32.

Cite this article as: Rengaraj S, Vinayagam S, Soukath S. Spontaneous heterotopic triplet pregnancy: rare case report. Int J Reprod Contracept Obstet Gynecol 2016;5:4496-8. 